Universidad

:

BIBLIOTECA

Document downloaded from the institutional repository of the University of Alcala: https://ebuah.uah.es/dspace/

This is a postprint version of the following published document:

Xu, D. et al., 2018. A facile and efficient single-step approach for the fabrication of vancomycin functionalized polymer-based monolith as chiral stationary phase for nano-liquid chromatography. Journal of Chromatography A, 1557, pp.43-50,

which has been published in final form at DOI:10.1016/i.chroma.2018.05.004

This article may be used for non-commercial purposes in accordance with Wiley Terms and Conditions for Use of Self-Archived Versions.

(C) 2018 Elsevier
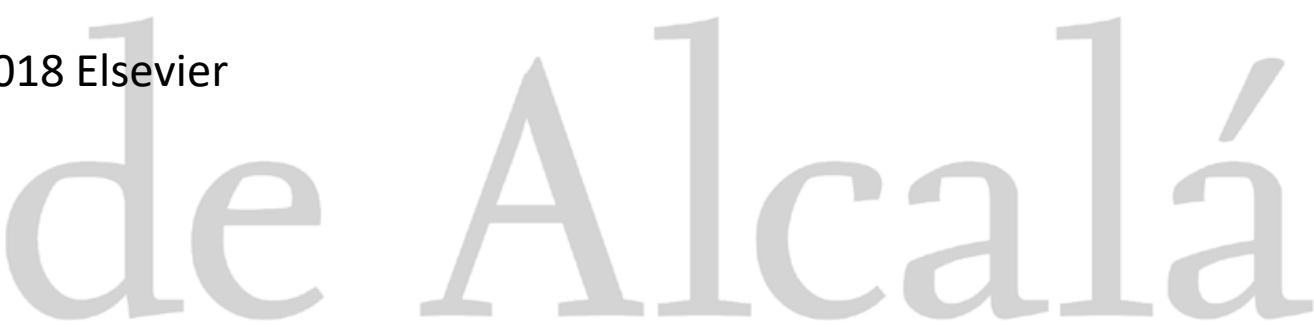

(Article begins on next page)

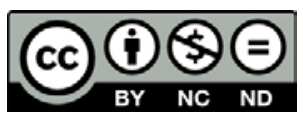

This work is licensed under a

Creative Commons Attribution-NonCommercial-NoDerivatives

4.0 International License. 

9

\title{
A facile and efficient single-step approach for the fabrication of vancomycin functionalized polymer-based monolith as chiral stationary phase for nano-liquid chromatography
}

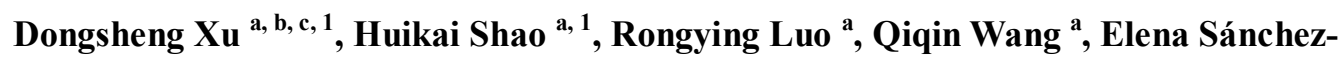 \\ López $^{c}$, Salvatore Fanali ${ }^{\text {d }}$, Maria Luisa Marina ${ }^{\mathrm{c}, \mathrm{e}} *$, Zhengjin Jiang ${ }^{\mathrm{a}, \mathrm{b}, \text { * }}$
}

a Institute of Pharmaceutical Analysis, College of Pharmacy, Jinan University, Guangzhou 510632, China.

${ }^{b}$ Department of Pharmacy and Guangdong Province Key Laboratory of Pharmacodynamic Constituents of Traditional Chinese Medicine \& New Drug Research, Jinan University, Guangzhou 510632, China.

${ }^{c}$ Departamento de Química Analítica, Química Física e Ingeniería Química, Universidad de Alcalá, Ctra. Madrid-Barcelona Km. 33.600, 28871 Alcalá de Henares (Madrid), Spain.

${ }^{d}$ PhD School in Natural Science and Engineering, University of Verona, Strada Le Grazie, 15 37129 Verona, Italy.

e Instituto de Investigación Química “Andrés M. del Río” (IQAR), Universidad de Alcalá, Ctra. Madrid-Barcelona Km. 33.600, 28871 Alcalá de Henares (Madrid), Spain.

(1)

5
7 0 1 2

${ }^{1}$ These authors contributed equally to this work.

* Corresponding authors. Tel: +34 918854935

${ }^{*}$ Corresponding authors. Tel: +86 2085223604

E-mail: mluisa.marina@uah.es (M. L. Marina),jzjjackson@hotmail.com (Z. J. Jiang) 
Abstract: A facile single-step preparation strategy for fabricating vancomycin functionalized organic polymer-based monolith within $100 \mu \mathrm{m}$ fused-silica capillary was developed. The synthetic chiral functional monomer, i.e 2-isocyanatoethyl methacrylate (ICNEML) derivative of vancomycin, was co-polymerized with the crosslinker ethylene dimethacrylate (EDMA) in the presence of methanol and dimethyl sulfoxide as the selected porogens. The co-polymerization conditions were systematically optimized in order to obtain satisfactory column performance. Adequate permeability, stability and column morphology were observed for the optimized poly(ICNEML-vancomycin-co-EDMA) monolith. A series of chiral drugs were evaluated on the poly(ICNEML-vancomycin-co-EDMA) monolith in either polar organic-phase or reversed-phase modes. After the optimization of separation conditions, baseline or partial enantioseparation were obtained for series of drugs including thalidomide, colchicine, carteolol, salbutamol, clenbuterol and several other $\beta$-blockers. The proposed single-step approach not only resulted in a vancomycin functionalized organic polymer-based monolith with good performance, but also significantly simplified the preparation procedure by reducing time and labor.

Keywords: Vancomycin, Enantioseparation, Organic polymeric monolith, Nano-LC 


\section{Introduction}

Although a large number of chiral stationary phases (CSPs) are available on the market, the development of novel CSPs still attracts considerable interest [1-2]. Recently, increasing efforts have been directed toward the development of organic polymer-based chiral monolithic columns because of their excellent permeability, $\mathrm{pH}$ stability, low resistance to mass transfer and high performance [3-4]. So far, various chiral selectors functionalized polymer-based chiral monoliths have been reported, such as cyclodextrin and its derivatives [5-6], quinidine and its derivatives [7-9], cellulose derivatives [10], proteins [11, 12], macrocyclic antibiotics [13-14], crown ethers [15] and chiral ion-exchangers [16].

Over the years, the vancomycin-type glycopeptide antibiotics have been proved to be a versatile class of chiral selectors for enantioseparation in polar organic-phase, normal-phase and reversed-phase modes since their enantioselectivity was demonstrated by Armstrong et al. [17]. However, very few vancomycin functionalized polymer-based monoliths have been reported. So far, only Maruška and coworkers developed a multi-step post-column modification strategy for immobilizing vancomycin onto the surface of organic polymeric monolith at the turn of the century [13-14]. The polymeric support was firstly prepared through in situ copolymerization of $N$-(hydroxymethyl) acrylamide, allyl glycidyl ether and piperazine diacrylamide with vinyl sulfonic acid within $100 \mu \mathrm{m}$ I.D. capillaries. Subsequently, vancomycin was introduced onto the polymeric skeleton via reductive amination of the aldehyde groups converted from epoxy groups. Later on, they simplified the preparation procedure by replacing allyl glycidyl ether with $N, N^{\prime}$-diallyltartardiamide, which can be easily cleaved into two aldehyde groups using periodate treatment. The vancomycin functionalized polymer-based monoliths prepared through both ways exhibited good enantioselectivity for racemic compounds in capillary electrochromatography (CEC). However, the authors did not provide any column-to-column and batch-to-batch repeatability data in their studies. To the best of our knowledge, there is no other report about vancomycin functionalized polymer-based monoliths. This may be partially attributed to some disadvantages associated with multi-step preparation strategy, such as time-consuming, laborious and probably dissatisfactory repeatability. Vancomycin functionalized silica-based monoliths were also prepared through multi-step preparation strategy [18-21]. Hsieh et al. recently developed a single-step in situ solgel approach for preparing vancomycin functionalized silica-based monolith [22]. A 
sol-gel precursor containing vancomycin was synthesized and copolymerized with skeleton precursor to form a porous silica-based monolith. The proposed single-step approach not only resulted in a chiral column with good efficiency and enantioselectivity for many basic enantiomers, but also significantly simplified the preparation procedure. Aiming at reducing the time and labor associated with the fabrication of vancomycin functionalized organic polymer-based monoliths, it would be of high interest to develop a single-step copolymerization approach as well.

In this work, a chiral functional monomer, i.e 2-isocyanatoethyl methacrylate (ICNEML) derivative of vancomycin (ICNEML-vancomycin), was first synthesized. It was then in situ copolymerized with the cross-linker ethylene dimethacrylate (EDMA) in a binary porogen system of methanol and dimethyl sulfoxide (DMSO). The polymerization conditions were systematically optimized in order to obtain satisfactory permeability, column efficiency and enantioresolution. The enantioresolution capability of the optimized poly(ICNEML-vancomycin-co-EDMA) was evaluated by analyzing a series of chiral drugs in either polar organic-phase or reversed-phase modes. The enantioseparation conditions, including the organic solvent type and concentration, the buffer concentration and the $\mathrm{pH}$ of the mobile phase, were also carefully optimized.

\section{Materials and methods}

\subsection{Reagents and samples}

2,2'-azobisisobutyronitrile (AIBN), 3-(trimethoxysilyl)-propylmethacrylate ( $\gamma$ MAPS), ethylene dimethacrylate (EDMA), 2-isocyanatoethyl methacrylate (ICNEML), DMSO, methanol (MeOH), ethanol, 1,4-butanediol, 1-propanol, tetrahydrofuran (THF), cyclohexane, 1-dodecanol and toluene, acetonitrile (ACN), triethylamine (TEA), acetic acid (HAc), pyridine, acetone and vancomycin hydrochloride were acquired from Aladdin Chemicals (Shanghai, China). Acebutolol, carteolol, sotalol, propranolol, pindolol, tertaolol, clenbuterol, salbutamol and thalidomide were obtained from Energy Chemical (Shanghai, China). Colchicine was purchased from Sigma (Missouri, USA). The fused-silica capillaries (375 $\mu$ m O.D. $\times 100 \mu \mathrm{m}$ I.D.) were obtained from Ruifeng Chromatography Ltd. (Hebei, China). Distilled water was purified using a Milli-Q system (Massachusetts, USA). Polar organic mobile phases were set up by mixing the desired ratio of $\mathrm{ACN}$ and $\mathrm{MeOH}$, and then adding various amount of TEA and HAc. All mobile phases were subjected to filtration through a $0.22-\mu \mathrm{m}$ membrane and sonication degas prior to use.

\subsection{Instrumentations}


Molecular masses were determined on a Waters Synapt G2 TOF mass spectrometer (Milford, USA). A Jinghong DKS22 water bath (Shanghai, China) was used for thermally initiated copolymerization. Scanning electron microscopy (SEM) experiments were performed with a Zeiss Gemini ultra-55 SEM (Deutschland, Germany) at an acceleration voltage of $5 \mathrm{kV}$. All nano-LC experiments were conducted on a nano-LC instrument, laboratory assembled. The system consists of a DiNa nano gradient pump (Tokyo, Japan), a Shimadzu SPD-15C UV detector (Kyoto, Japan) with a lab-made on-column detection cell and a Valco four-port injection valve with $20 \mathrm{~nL}$ internal loop (Houston, USA). All data acquisition and analysis were carried out with Unimicro Trisep ${ }^{\mathrm{TM}}$ Workstation 2003 (Shanghai, China). The $\mathrm{pH}$ values of buffer solutions were measured by a Sartorius PB-10 pH meter (Göttingen, Germany).

\subsection{Synthesis of the chiral functional monomer ICNEML-vancomycin}

The nucleophilic addition of amine or hydroxyl groups were often used for the derivatization of vancomycin [23-24]. In this study, ICNEML was chosen as the derivatization reagent to modify vancomycin through the nucleophilic addition reaction. For the schematic representation of the synthesis of the novel ICNEML-vancomycin monomer, see Fig. 1. In brief, vancomycin hydrochloride (60 mg, $0.04 \mathrm{mmol}$ ) was dissolved in DMSO (0.3 mL). Then, pyridine $(0.4 \mathrm{~mL})$ and ICNEML (10 $\mu \mathrm{L}, 0.07 \mathrm{mmol})$ were added into the mixture and stirred for $24 \mathrm{~h}$ under nitrogen at room temperature. After adding acetone $(8 \mathrm{~mL})$ and stirring for another $10 \mathrm{~min}$, a white precipitate was collected by centrifugation at $4000 \mathrm{rpm}$ for $5 \mathrm{~min}$ and washed with acetone for five times. Finally, the precipitate was dried under vacuum to give the target monomer (light white solid). The molecular formula of ICNEML-vancomycin was established as $\mathrm{C}_{73} \mathrm{H}_{84} \mathrm{~N}_{10} \mathrm{O}_{27} \mathrm{Cl}_{2}$ from its HR-ESI-MS (m/z: $1603.4965[\mathrm{M}+\mathrm{H}]^{+}$, calculated for $\mathrm{C}_{73} \mathrm{H}_{85} \mathrm{~N}_{10} \mathrm{O}_{27} \mathrm{Cl}_{2}$ : 1603.4963) in Fig. S1.

\subsection{Preparation of the poly(ICNEML-vancomycin-co-EDMA) monolith columns}

Prior to the polymerization, the fused-silica capillaries were pretreated with $\gamma$-MAPS to provide the anchoring sites for the bulk polymer [25]. Then, the monomer ICNEMLvancomycin, the binary porogens (DMSO and $\mathrm{MeOH}$ ), the crosslinker EDMA and the initiator AIBN were accurately weighted and mixed into a homogenous solution in a 2 $\mathrm{mL}$ of vial. The mixture was sonicated and degassed for $5 \mathrm{~min}$, and then introduced into $20 \mathrm{~cm}$ long pretreated capillaries. Both ends of the capillaries were sealed with rubber plugs and submerged into the water bath at $60{ }^{\circ} \mathrm{C}$ for $12 \mathrm{~h}$. The unreacted porogens and 
chemicals were removed by flushing the column with methanol. The obtained monolith was cut to $15 \mathrm{~cm}$ for nano-LC analysis. A $2-5 \mathrm{~mm}$ length of the monolith was used for scanning electron microscopy (SEM) analysis.

\section{Results and discussion}

\subsection{Preparation and characterization of the poly(ICNEML-vancomycin-co- EDMA) monolithic column}

Porogen selection is a critical step in the preparation of polymer-based monolithic column since the type and amount of porogens influence the porosity, morphology, permeability and even the chromatographic efficiency of the monolith. A suitable porogenic solvent or solvent combination should be able to dissolve all components (including functional monomer, initiator and cross-linker) and does not react each other chemically. In this study, several commonly used polar solvents (DMSO, water, $\mathrm{MeOH}$, ethanol, 1,4-butanediol and 1-propanol) and non-polar solvents (THF, cyclohexane, toluene, 1-dodecanol) were initially investigated. The solubility of monomers, the permeability and visual appearance of the monoliths prepared under each porogen system were inspected using nano-LC and microscopy. Based upon our initial experiments, both ICNEML-vancomycin and EDMA showed good solubility in a binary solvent system consisting of $\mathrm{MeOH}$ and DMSO (75/25, w/w). In addition, the resulting monoliths also exhibited a uniform dark structure and good permeability. Therefore, these solvents were selected for the following systematical optimization of the polymerization conditions, including the weight fraction of the porogens, the weight fraction of EDMA and the composition of porogenic mixture. Acebutolol was selected as test analyte using a mobile phase consisting of $\mathrm{MeOH} / \mathrm{ACN} / \mathrm{TEA} / \mathrm{HAc}$ $(80 / 20 / 0.08 / 0.02, \mathrm{v} / \mathrm{v} / \mathrm{v} / \mathrm{v})$. The influence of the porogen content was first studied by varying the weight fraction of $\mathrm{MeOH} / \mathrm{DMSO}(75 / 25$, w/w) at three different percentage, i.e. 71\% (Column C1), 75\% (Column C2) and 79\% (Column C3), while keeping constant the other conditions (see Table 1). The results showed that the porogens content had a significant influence on the column permeability. As the percentage of porogens increased, the backpressure diminished. The column C1 prepared with $71 \%$ porogens exhibited a very high backpressure. When comparing the enantioresolution obtained for acebutolol enantiomers, the column C2 exhibited a higher enantioresolution, and therefore, it was selected for the following studies.

Second, the content of the crosslinker EDMA in the monomer mixture was optimized since it can also influence both the column permeability and 
enantioselectivity. As the weight fraction of EDMA in the monomer mixture increased from $20.8 \%$ (column C5) to $25.0 \%$ (column C2), the back-pressure and enantioresolution dramatically increased from 3.6 to $7.5 \mathrm{MPa}$ and 0.51 to 1.45 , respectively. However, further increasing the EDMA content to $29.2 \%$ (column C4) resulted in a slightly lower $R_{\mathrm{S}}$ value (1.38) and higher backpressure (9.5 MPa) when compared to column C2. Thus, 25.0\% EDMA was considered for further optimizations. Finally, the influence of the porogenic mixture composition (MeOH and DMSO) was investigated by varying the weight content of $\mathrm{MeOH}$ from $70 \%$ (column C6) to $80 \%$ (column C7). The increase of the $\mathrm{MeOH}$ content caused a decrease of the back-pressure from 9.8 to $4.7 \mathrm{MPa}$. $75 \% \mathrm{MeOH}$ (column C2) allowed for the highest $R_{\mathrm{s}}$ value under a reasonable backpressure.

Based on these optimization experiments, the polymerization mixture containing $25 \%$ monomers (ICNEML-vancomycin/EDMA, 75/25, w/w) and 75\% porogens (MeOH/DMSO, 75/25, w/w) were selected for following studies. The morphology of the optimized poly (ICNEML-vancomycin-co-EDMA) (column C2) monolithic column was evaluated by scanning electron microscopy (SEM). As shown in Fig. 2, the SEM images indicated that the column $\mathbf{C 2}$ has a morphology of continuous skeleton and large through-pores, and the monolithic rod is tightly anchored on the inner wall of the capillary column.

\subsection{Permeability and reproducibility of the poly(ICNEML-vancomycin-co- EDMA) monolithic column}

The permeability $K$ of a monolithic column can be calculated according to the following equation [26-27]:

$$
K=\frac{u \eta \mathrm{L}}{\Delta \mathrm{P}}
$$

where $u$ is the linear velocity of the mobile phase, $\mathrm{L}$ is the length of the column, $\Delta \mathrm{P}$ is the pressure drop across the column, and $\eta$ is the dynamic viscosity of the eluent. Toluene (ACN or $\mathrm{MeOH}$ as mobile phase) and thiourea (water/ACN (50/50, v/v) as mobile phase) were chosen as the dead time markers. As shown in Table 2, the calculated $K$ values for the column $\mathbf{C 2}$ were $2.78 \times 10^{-14}, 4.16 \times 10^{-14}$ and $1.97 \times 10^{-14}$ $\mathrm{m}^{2}$ when using $\mathrm{MeOH}, \mathrm{ACN}$ and water/ACN $(50 / 50, \mathrm{v} / \mathrm{v})$ as the mobile phases, respectively. It is worth noting that these determined permeability values are quite similar, indicating the swell or shrink of the optimized poly(ICNEML-vancomycin-coEDMA) monolith in solvents with different polarities is little. 
Repeatability and reproducibility of some studied parameters on the poly (ICNEMLvancomycin-co-EDMA) monolithic column were evaluated through calculating the RSD values for $k_{1}, k_{2}, \alpha$ and $R_{s}$ of the racemic test compound acebutolol using a mixture of $\mathrm{MeOH} / \mathrm{ACN} / \mathrm{TEA} / \mathrm{HAc}(85 / 15 / 0.08 / 0.02, \mathrm{v} / \mathrm{v} / \mathrm{v} / \mathrm{v})$ as mobile phase (Table 3). The column-to-column reproducibility $(\mathrm{n}=6)$ for retention factors $\left(k_{1}\right.$ and $\left.k_{2}\right)$ were $2.36 \%$, while the batch-to-batch $(n=6)$ RSD values were $2.72 \%$ and $2.36 \%$. The run-to-run repeatability $(\mathrm{n}=6)$ for $k_{1}$ and $k_{2}$ was also adequate with $\mathrm{RSD}$ values of $1.98 \%$ and $2.36 \%$, in addition to day-to-day repeatability $(n=6)$ which RSD values were $3.03 \%$ and $3.42 \%$, respectively. RSD values of $\alpha$ and $R_{s}$ were also satisfactory $(\leq 5.92 \%)$. These data demonstrated that the poly (ICNEML-vancomycin-co-EDMA) monolithic column has a satisfactory reproducibility for enantioseparation in nano-LC.

\subsubsection{Polar organic phase mode}

Based on our experience and on the data reported in literature [28] a mobile phase containing ACN-MeOH and TEA-HAc was selected as polar organic mobile phase. It has been reported that in any LC-based enantioseparation, the composition of mobile phase affects the enantioselectivity through changing the charge-charge interaction, hydrogen bonding and $\pi-\pi$ interaction, among other factors [29-30]. Therefore, the $\mathrm{MeOH} / \mathrm{ACN}$ content and additives content (TEA/HAc ratio and their total concentration) were modified to evaluate their effect on the enantioresolution of carteolol, acebutolol and sotalol. Due to the fact that the observed behavior was quite the same for these three compounds, only figure of merits for carteolol will be shown. The influence of the concentration ratio of $\mathrm{MeOH} / \mathrm{ACN}$ on the retention factor and enantioresolution for carteolol was evaluated by keeping constant TEA/HAc content. As shown in Fig. 3a and b, with increasing $\mathrm{MeOH}$ concentration from $60 \%$ to $85 \%$ $(\mathrm{v} / \mathrm{v})$, the enantioresolution increased reaching its maximum value, and then decreased when the $\mathrm{MeOH}$ concentration further raised from $85 \%$ to $100 \%(\mathrm{v} / \mathrm{v})$. The retention factor $\left(k_{1}\right)$ decreased gradually with the increase of the concentration of $\mathrm{MeOH}$. On the other hand, the enantioselectivity factor $(\alpha)$ increased by raising $\mathrm{MeOH}$ content, while the column efficiency increased with the increase of $\mathrm{MeOH}$ content from $60 \%$ to $90 \%$ $(\mathrm{v} / \mathrm{v})$ and then diminished at $100 \%(\mathrm{v} / \mathrm{v})$. As a compromise between enantioresolution and column efficiency, $85 \%$ (v/v) $\mathrm{MeOH}$ was chosen as the mobile phase. These results also agreed with the previous studies on the vancomycin based chiral stationary phases [22] because higher $\mathrm{MeOH}$ content in combination with a small amount of acid/base 
additives might contribute to less nonselective hydrogen bonding interactions for carteolol enantiomers and vancomycin stationary phases.

As can be observed in Fig. 4a, the use of an appropriate TEA/HAc concentration and ratio could be of paramount importance in influencing both enantioseparation and column efficiency. Therefore, the ratio of the TEA/HAc (\%,v/v) in the mobile phase was varied from1:3 to 9:1, while the total concentration of TEA and HAc was kept at $0.1 \%(\mathrm{v} / \mathrm{v})$ and the ratio of $\mathrm{MeOH} / \mathrm{ACN}$ kept constant at $(85 / 15, \mathrm{v} / \mathrm{v})$. The increase of the ratio of TEA/HAc from 1:3 to 4:1 caused an increase of enantioresolution. Then this parameter decreased as the ratio further increased to 9:1. This is because the hydrogen bonding is the most important in this mode, so the stronger interaction between the CSP and enantiomer with the $\mathrm{Ac}^{-}$content decreased in the mobile phase. However, the ionization of the basic compounds was weak as the TEA/HAc ratio increased from 4:1 to 9:1, and this would weaken the interaction. On the contrary, the chromatographic efficiency showed a different trends (decreased almost linearly by increasing the TEA/HAc ratio from 1:3 to 9:1). As a compromise to achieving optimum enantioresolution and column chromatographic efficiency, the ratio of $4: 1$ for TEA/HAc $(0.08 \% / 0.02 \%, \mathrm{v} / \mathrm{v})$ was chosen as the mobile phase additive.

Fig. 4b shows the effect of total concentration of TEA and HAc on the column efficiency. As can be seen, the increase of the total concentration of TEA and HAc in the mobile phase from $0.01 \%$ to $0.2 \%(\mathrm{v} / \mathrm{v})$ caused a raising of number of theoretical plates, while the highest enantioresolution was obtained at $0.1 \%(\mathrm{v} / \mathrm{v})$. Therefore, a total concentration of TEA and HAc of $0.1 \%(\mathrm{v} / \mathrm{v})$ was selected as the optimum mobile phase modifier mixture.

Under the optimal conditions (mobile phase consisting of MeOH/ACN/TEA/HAc $(85 / 15 / 0.08 / 0.02, \mathrm{v} / \mathrm{v} / \mathrm{v} / \mathrm{v}))$, eight racemic compounds were tested. As shown in Table 4 and Fig. 5, good $R_{s}$ values were obtained for most of the compounds.

\subsubsection{Reversed phase mode}

As reported in previous studies [13, 14], the basic compound carteolol was not enantio-resolved on the vancomycin functionalized monolith in the reversed phase elution mode where ACN was mainly used [22]. In our preliminary experiments, no enantioresolution of this analyte was observed employing similar conditions. Therefore, $\mathrm{MeOH}$ instead of ACN was chosen for the enantioseparation of carteolol to investigate the effect of $\mathrm{MeOH}$ concentration on the enantioseparation of carteolol. As shown in Fig. 6a, both retention factor $\left(k_{1}\right)$ and enantioselectivity factor $(\alpha)$ increased by varying 
$\mathrm{MeOH}$ content in the mobile phase in the range 80-98\% (v/v) with the highest values at $98 \%(\mathrm{v} / \mathrm{v})$. This effect can be explained with a consequent stronger interaction of the studied enantiomers with vancomycin CSP because higher $\mathrm{MeOH}$ concentration combined with TEAA would lead to less nonselective hydrogen interaction [14]. As shown in Fig. 6b, the $\mathrm{MeOH}$ content also had a strong influence on the enantioresolution and column efficiency, and a slightly higher enantioresolution and column efficiency was obtained when the mobile phase contained 90\% (v/v) $\mathrm{MeOH}$. Hence, $90 \%$ (v/v) $\mathrm{MeOH}$ was selected as the optimum mobile phase for the enantioseparation of carteolol.

Due to the fact that in reversed phase mode the $\mathrm{pH}$ and content of buffer solution also played an important role for enantioseparation, they were investigated. Fig. 7a shows the effect of the buffer $\mathrm{pH}$ present in the mobile phase on enantioresolution and column chromatographic efficiency. Both parameters increased with increasing the buffer $\mathrm{pH}$ value from 4.5 to 6.0 and the optimum $\mathrm{pH}$ value was 5.5. In order to improve the enantioseparation, various concentration of TEAA buffer were evaluated (Fig. 7b). A decrease of the enantioresolution factors with increasing TEAA buffer content can be observed, while the column chromatographic efficiency raised when the TEAA buffer content increased from $0.1 \%$ to $1 \%(\mathrm{v} / \mathrm{v})$ and then decreased. As a compromise between enantioresolution and column efficiency, 0.5\% TEAA $(\mathrm{pH}=5.5) / \mathrm{MeOH}(10 / 90, \mathrm{v} / \mathrm{v})$ was selected as the mobile phase. Carteolol enantiomers were baseline separated with $R_{s}$ value of 1.59 as shown in Fig. 8a. Clenbuterol, salbutamol, acebutolol and several other $\beta$-blockers were also tested using $0.5 \%$ TEAA $(\mathrm{pH}=5.5) / \mathrm{MeOH}(10 / 90, \mathrm{v} / \mathrm{v})$ as the mobile phase. However, it was found that the enantioresolutions of these compounds were not satisfactory.

Colchicine was also tested under the above optimized conditions, unfortunately, no baseline enantioseparation was achieved. Therefore, a similar optimization process was performed. Under the optimized condition, i.e. $50 \mathrm{mM}$ ammonium acetate $(\mathrm{pH}=5.5) /$ water/ACN $(5 / 5 / 90, \mathrm{v} / \mathrm{v} / \mathrm{v})$, a baseline separation with $R_{s}$ value of 2.92 was obtained for colchicine enantiomers (Fig. 8b). Due to the fact that thalidomide enantiomers were separated in previous reports using 0.2\% TEAA, pH 4.5/ACN (80:20, $\mathrm{v} / \mathrm{v})$ as mobile phase [22], these conditions were employed for the separation of thalidomide on the poly (ICNEML-vancomycin-co-EDMA) monolith column. It was found that the enantioresolution was still good (3.27) but the analysis time was too long ( $\geq 80 \mathrm{~min}$ ). Thus, the mobile phase was re-optimized in which $0.5 \%$ TEAA buffer 
$(\mathrm{pH}=5.4) / \mathrm{ACN}(70 / 30, \mathrm{v} / \mathrm{v})$ offered the best output in terms of enantioresolution and analysis time (Fig. 8c). As shown in Table 5, carteolol, colchicine and thalidomide enantiomers can be completely separated on the poly (ICNEML-vancomycin-coEDMA) monolith column under the reversed-phase mode by nano-LC.

\section{Conclusion}

This study has demonstrated a novel and facile method to synthesize vancomycin functionalized organic polymeric monolith through a single-step approach, which simplifies the fabrication of previous studies. The prepared monolith has been proven to possess large through-pores and a good mechanical stability. Satisfactory column permeability and good enantioselectivity were obtained on the optimum poly(ICNEML-vancomycin-co-EDMA) monolith. The mobile phase composition of different buffer $\mathrm{pH}$, organic modifier content and buffer concentration which could influence the enantioseparation was further investigated both in the polar organic and reversed phase modes for enantioseparation of $\beta$-blockers. The vancomycin functionalized organic polymer monolith displayed baseline separation for most of the selected enantiomers in both chromatographic modes.

\section{Acknowledgements}

M. L. Marina and E. Sánchez-López thank the Ministry of Economy and Competitiveness (Spain) for research project CTQ2013-48740-P. D. Xu and E. Sánchez-López thank the Comunidad of Madrid and European funding from FEDER program for their contracts (AVANSECAL-CM program, ref. S2013/ABI-3028). This work was also supported by the Science and Technology Planning Project of Guangdong Province, China (2016A040403056 and 2015A020211018) and the International Science \& Technology Cooperation Program of Guangzhou, China (201807010022).

(1) 


\section{References}

[1] S. Fanali, Nano-liquid chromatography applied to enantiomers separation, J. Chromatogr. A 1486 (2017) 20-34.

[2] B. Chankvetadze, Recent developments on polysaccharide-based chiral stationary phases for liquid-phase separation of enantiomers, J. Chromatogr. A 1269 (2012) 26-51.

[3] J.L. Guo, Y.J. Lin, Y. Xiao, J. Crommen, Z.J. Jiang, Recent developments in cyclodextrin functionalized monolithic columns for the enantioseparation of chiral drugs, J. Pharm. Biomed. Anal. 130 (2016) 110-125.

[4] N.W. Smith, Z.J. Jiang, Developments in the use and fabrication of organic monolithic phases for use with high-performance liquid chromatography and capillary electrochromatography, J Chromatogr A, 1184 (2008) 416-440.

[5] Q.X. Zhang, J.L. Guo, F. Wang, J. Crommen, Z.J. Jiang, Preparation of a $\beta$ cyclodextrin functionalized monolith via a novel and simple one-pot approach and application to enantioseparations, J. Chromatogr A, 1325 (2014) 147-154.

[6] Y.J. Lin, J.L. Guo, H. Lin, J.C. Wang, G. W. Somsen, J. Crommen, Z. Jiang, Effect of fabrication strategy on the enantioseparation performance of $\beta$-cyclodextrinfunctionalized polymethacrylate monoliths: A comparative evaluation J. Sep. Sci. 40 (2017) 3754-3762.

[7] Q.Q. Wang, E. Sánchez-López, H. Han, H.H. Wu, P.J. Zhu, J. Crommen, M. L. Marina, Z.J. Jiang, Separation of N-derivatized di- and tri-peptide stereoisomers by micro-liquid chromatography using a quinidine-based monolithic columnAnalysis of 1-carnosine in dietary supplements, J. Chromatogr. A, 1428 (2016) 176-184.

[8] Q.Q. Wang, P.J. Zhu, M. Ruan, H.H. Wu, K. Peng, H. Han, G. W. Somsen, J. Crommen, Z.J. Jiang, Chiral separation of acidic compounds using an O-9-(tertbutylcarbamoyl) quinidine functionalized monolith in micro-liquid chromatography, J. Chromatogr. A 1444 (2016) 64-73.

[9] M. Lämmerhofer, E. C. Peters, C. Yu, F. Svec, J. M. J. Frechet, Chiral monolithic columns for enantioselective capillary electrochromatography prepared by copolymerization of a monomer with quinidine functionality. 1. Optimization of 
polymerization conditions, porous properties, and chemistry of the stationary phase, Anal. Chem. 72 (2000) 4614-4622.

[10] X.L. Dong, R.A. Wu, J. Dong, M.H. Wu, Y. Zhu, H.F. Zou, Polyacrylamide-based monolithic capillary column with coating of cellulose tris(3,5-dimethylphenyl-

[17] D. W. Armstrong, Y. Tang, S. Chen, Y. Zhou, C. Bagwill, J. R. Chen, Macrocyclic antibiotics as a new class of chiral selectors for liquid chromatography, Anal. Chem. 66 (1994) 1473-1484.

[18] X.L. Dong, J. Dong, J.J. Ou, Y. Zhu, H.F. Zou, Preparation and evaluation of a vancomycin immobilized silica monolith as chiral stationary phase for CEC, Electrophoresis 28 (2007) 2606-2612.

[19] G.S. Ding, A.N. Tang, Capillary electrochromatographic separation of racemates 
on a norvancomycin-bonded monolithic column under reversed-phase conditions, J Chromatogr. A, 1208 (2008) 232-238.

[20] A.N. Tang, X.N. Wang, G.S. Ding, X.P. Yan, On-line preconcentration and enantioseparation of thalidomide racemates by CEC with the hyphenation of octyl and norvancomycin monoliths, Electrophoresis 30 (2009) 682-688.

[21] E. Pittler, M.G. Schmid, enantioseparation of dansyl amino acids by HPLC on a monolithic column dynamically coated with a vancomycin derivative, Biomed. Chromatogr. 24 (2010) 1213-1219.

[22] M.L. Hsieh, L.K. Chau, Y.S. Hon, Single-step approach for fabrication of vancomycin-bonded silica monolith as chiral stationary phase, J Chromatogr. A, 1358 (2014) 208-216.

[23] A. Berthod, U.B. Nair, C. Bagwill, D.W. Armstrong, Derivatized vancomycin stationary phases for LC chiral separations, Talanta 43 (1996) 1767.

[24] U. B. Nair, S. S. C. Chang, D. W. Armstrong, Y. Y. Rawjee, D. S. Eggleston, Elucidation of vancomycin's enantioselective binding site using its copper complex, J. V. McArdle, Chirality 8 (1996) 590.

[25] B. Xiong, L. Zhang, Y. Zhang, H. Zou, J. Wang, Capillary electrochromatography with monolithic poly (styrene-co-divinylbenzene-co-methacrylic acid) as the stationary phase, J. High Resol. Chromatogr. 23 (2000) 67-72.

[26] Z.J. Jiang, N.W. Smith, P.D. Ferguson, M.R. Taylor, Hydrophilic interaction chromatography using methacrylate-based monolithic capillary column for the separation of polar analytes, Anal. Chem. 79 (2007) 1243-1250.

[27] J. Lin, S. Liu, J. Lin, X. Lin, Z. Xie, Novel highly hydrophilic methacrylate-based monolithic column with mixed-mode of hydrophilic and strong cation-exchange interactions for pressurized capillary electrochromatography, J. Chromatogr. A 1218 (2011) 4671-4677.

[28] S. M. Zarcero, I. Sierra, Comparative HPLC methods for $\beta$-blockers separation using different types of chiral stationary phases in normal phase and polar organic phase elution modes. Analysis of propranolol enantiomers in natural waters, J. Pharm. Biomed. Anal. 62 (2012) 33-41.

[29] T.L. Xiao, R.V. Rozhkov, D.W. Armstrong, Separation of the enantiomers of substituted dihydrofurocoumarins by HPLC using macrocyclic glycopeptide chiral stationary phases, Anal. Bioanal. Chem. 377 (2003) 693-654. 
[30] C. Karlsson, L. Karlsson, D.W. Armstrong, P.K. Owens, Evaluation of a vancomycin chiral stationary phase in capillary electrochromatography using polar organic and reversed-phase modes, Anal. Chem. 72 (2000) 4394-4401.

460 
Figures captions:

462

463

464

465

466

467

468

469

470

471

472

473

474

475

476

477

478

479

480

481

482

483

484

485

486

487

488

489

490

491

492

493

Fig. 1. Schematic representation of the synthesis of the ICNEML-vancomycin.

Fig. 2. SEM images of the poly (ICNEML-vancomycin-co-EDMA) monolithic column at different magnifications.

Fig. 3. Effect of the $\mathrm{MeOH}$ content on (a) retention factor and enantioselectivity; (b) enantioresolution and column chromatographic efficiency for carteolol enantiomers in the polar organic-phase mode. Conditions: column dimensions: $15 \mathrm{~cm} \times 100 \mu \mathrm{m}$ I.D.; mobile phase: $\mathrm{MeOH} / \mathrm{ACN} / \mathrm{TEA} / \mathrm{HAc}$ (at the desired ratio of $\mathrm{MeOH}$ and ACN/0.08/0.02, v/v/v/v); UV detection wavelength: $230 \mathrm{~nm}$; total flow rate: 400 $\mathrm{nL} / \mathrm{min}$; injection volume: $20 \mathrm{~nL}$.

Fig. 4. Effect of the ratio (a) and content (b) of TEA/HAc on enantioresolution and column chromatographic efficiency for carteolol enantiomers in the polar organicphase mode. Conditions: mobile phase: (a) MeOH/ACN/TEA/HAc (85/15/at the desired ratio of TEA and HAc, v/v/v/v); (b) MeOH/ACN/TEA/HAc (85/15/at the desired content of TEA and HAc, v/v/v/v); other experimental conditions are the same as in Fig. 3.

Fig. 5. Enantioseparation of racemic compounds in polar organic-phase mode. Conditions: column dimensions: $15 \mathrm{~cm} \times 100 \mu \mathrm{m}$ I.D.; mobile phase: $\mathrm{MeOH} / \mathrm{ACN} / \mathrm{TEA} / \mathrm{HAc}(85 / 15 / 0.08 / 0.02, \mathrm{v} / \mathrm{v} / \mathrm{v} / \mathrm{v})$; UV detection wavelength: $230 \mathrm{~nm}$; total flow rate: $400 \mathrm{~nL} / \mathrm{min}$; injection volume: $20 \mathrm{~nL}$.

Fig. 6. Effect of the $\mathrm{MeOH}$ content on (a) retention factor $\left(k_{l}\right)$ and enantioselectivity factor $(\alpha)$; (b) enantioresolution and column chromatographic efficiency for carteolol enantiomers in the reversed-phase mode. Conditions: column dimensions: $15 \mathrm{~cm} \times 100$ $\mu \mathrm{m}$ I.D.; mobile phase: $0.5 \%$ TEAA, $\mathrm{pH}=5.5 / \mathrm{MeOH}$; UV detection wavelength: 230 $\mathrm{nm}$; total flow rate: $400 \mathrm{~nL} / \mathrm{min}$; injection volume: $20 \mathrm{~nL}$.

Fig. 7. Effect of TEAA buffer $\mathrm{pH}$ (a) and content (b) on enantioresolution and column chromatographic efficiency for carteolol enantiomers in the reversed-phase mode. 
494 Conditions: mobile phase: (a) 0.5\% TEAA/MeOH (10/90, v/v); (b) TEAA, $495 \mathrm{pH}=5.5 / \mathrm{MeOH}(10 / 90, \mathrm{v} / \mathrm{v})$; other experimental conditions are the same as in Fig. 6.

496

497 Fig. 8. Enantioseparation of (a) carteolol, (b) colchicine and (c) thalidomide in 498 reversed-phase mode. Conditions: column dimensions: $15 \mathrm{~cm} \times 100 \mu \mathrm{m}$ I.D.; mobile 499 phase: (a) $0.5 \%$ TEAA, $\mathrm{pH}=5.5 / \mathrm{MeOH}(10 / 90, \mathrm{v} / \mathrm{v})$; (b) $50 \mathrm{mM}$ ammonium acetate, $500 \mathrm{pH}=5.5 /$ water/ACN $(5 / 5 / 90, \mathrm{v} / \mathrm{v} / \mathrm{v})$; (c) $0.5 \%$ TEAA, $\mathrm{pH}=5.4 / \mathrm{ACN}(70 / 30, \mathrm{v} / \mathrm{v}) ; \mathrm{UV}$ 501 detection wavelength: $230 \mathrm{~nm}$ (a and c) or $243 \mathrm{~nm}$ (b); flow rate: $400 \mathrm{~nL} / \mathrm{min}$; injection 502 volume: $20 \mathrm{~nL}$.

503

504 


\section{Figures captions:}

Fig. 1. Schematic representation of the synthesis of the ICNEML-vancomycin.

Fig. 2. SEM images of the poly (ICNEML-vancomycin-co-EDMA) monolithic column at different magnifications.

Fig. 3. Effect of the $\mathrm{MeOH}$ content on (a) retention factor and enantioselectivity; (b) enantioresolution and column chromatographic efficiency for carteolol enantiomers in the polar organic-phase mode. Conditions: column dimensions: $15 \mathrm{~cm} \times 100 \mu \mathrm{m}$ I.D.; mobile phase: $\mathrm{MeOH} / \mathrm{ACN} / \mathrm{TEA} / \mathrm{HAc}$ (at the desired ratio of $\mathrm{MeOH}$ and ACN/0.08/0.02, v/v/v/v); UV detection wavelength: $230 \mathrm{~nm}$; total flow rate: 400 $\mathrm{nL} / \mathrm{min}$; injection volume: $20 \mathrm{~nL}$.

Fig. 4. Effect of the ratio (a) and content (b) of TEA/HAc on enantioresolution and column chromatographic efficiency for carteolol enantiomers in the polar organicphase mode. Conditions: mobile phase: (a) MeOH/ACN/TEA/HAc (85/15/at the desired ratio of TEA and HAc, v/v/v/v); (b) MeOH/ACN/TEA/HAc (85/15/at the desired content of TEA and HAc, v/v/v/v); other experimental conditions are the same as in Fig. 3.

Fig. 5. Enantioseparation of racemic compounds in polar organic-phase mode. Conditions: column dimensions: $15 \mathrm{~cm} \times 100 \mu \mathrm{m}$ I.D.; mobile phase: $\mathrm{MeOH} / \mathrm{ACN} / \mathrm{TEA} / \mathrm{HAc}(85 / 15 / 0.08 / 0.02, \mathrm{v} / \mathrm{v} / \mathrm{v} / \mathrm{v})$; UV detection wavelength: $230 \mathrm{~nm}$; total flow rate: $400 \mathrm{~nL} / \mathrm{min}$; injection volume: $20 \mathrm{~nL}$.

Fig. 6. Effect of the $\mathrm{MeOH}$ content on (a) retention factor $\left(k_{l}\right)$ and enantioselectivity factor $(\alpha)$; (b) enantioresolution and column chromatographic efficiency for carteolol enantiomers in the reversed-phase mode. Conditions: column dimensions: $15 \mathrm{~cm} \times 100$ $\mu \mathrm{m}$ I.D.; mobile phase: $0.5 \%$ TEAA, $\mathrm{pH}=5.5 / \mathrm{MeOH}$; UV detection wavelength: 230 $\mathrm{nm}$; total flow rate: $400 \mathrm{~nL} / \mathrm{min}$; injection volume: $20 \mathrm{~nL}$.

Fig. 7. Effect of TEAA buffer $\mathrm{pH}$ (a) and content (b) on enantioresolution and column chromatographic efficiency for carteolol enantiomers in the reversed-phase mode. 
Conditions: mobile phase: (a) $0.5 \%$ TEAA/MeOH (10/90, v/v); (b) TEAA, $\mathrm{pH}=5.5 / \mathrm{MeOH}(10 / 90, \mathrm{v} / \mathrm{v})$; other experimental conditions are the same as in Fig. 6.

Fig. 8. Enantioseparation of (a) carteolol, (b) colchicine and (c) thalidomide in reversed-phase mode. Conditions: column dimensions: $15 \mathrm{~cm} \times 100 \mu \mathrm{m}$ I.D.; mobile phase: (a) $0.5 \%$ TEAA, $\mathrm{pH}=5.5 / \mathrm{MeOH}(10 / 90$, v/v); (b) $50 \mathrm{mM}$ ammonium acetate, $\mathrm{pH}=5.5 /$ water/ACN $(5 / 5 / 90, \mathrm{v} / \mathrm{v} / \mathrm{v})$; (c) $0.5 \%$ TEAA, $\mathrm{pH}=5.4 / \mathrm{ACN}(70 / 30, \mathrm{v} / \mathrm{v})$; UV detection wavelength: $230 \mathrm{~nm}$ (a and c) or $243 \mathrm{~nm}$ (b); flow rate: $400 \mathrm{~nL} / \mathrm{min}$; injection volume: $20 \mathrm{~nL}$.

Table 1. Composition of the polymerization mixture used for the preparation of the poly (ICNEML-vancomycin-co-EDMA) monolith columns and their properties.

Table 2. Permeability of the poly (ICNEML-vancomycin-co-EDMA) monolith column

Table 3. Reproducibility of the poly (ICNEML-vancomycin-co-EDMA) monolith columns

Table 4. Enantioseparation of eight racemic compounds under the polar organic phase mode.

Table 5. Enantioseparation of three racemic compounds under the reversed phase mode. 
Figure 1

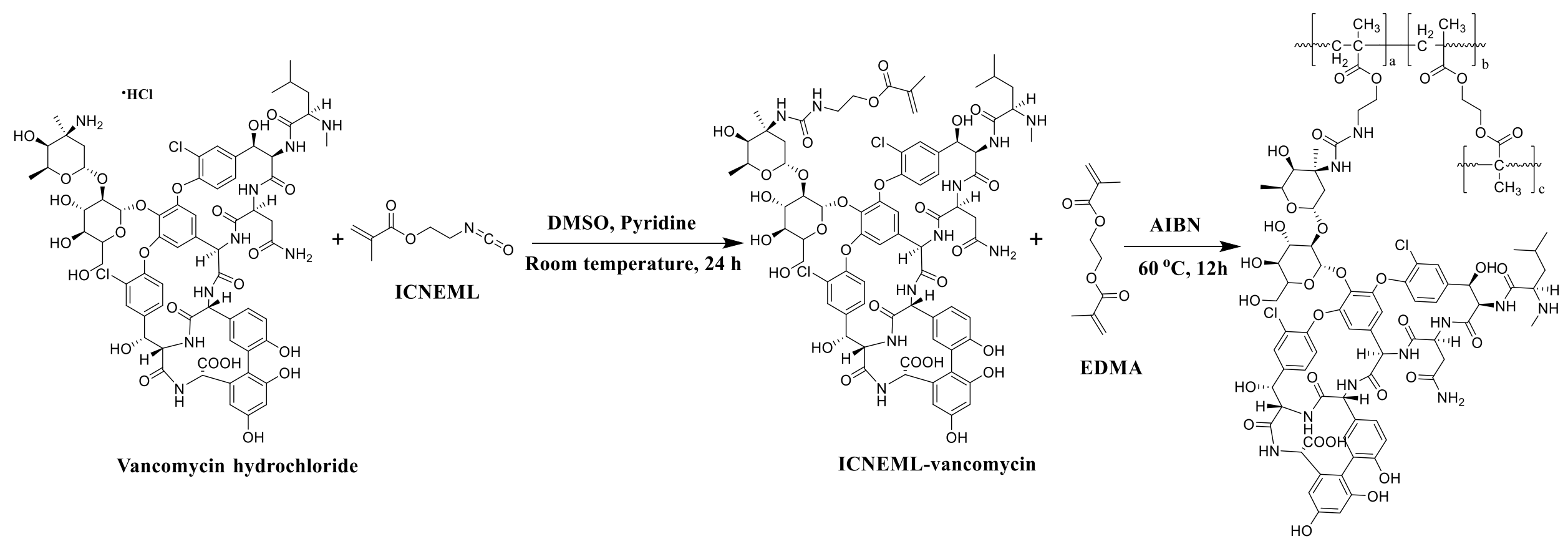

Poly (ICNEML-vancomycin-co-EDMA) 
Figure 2
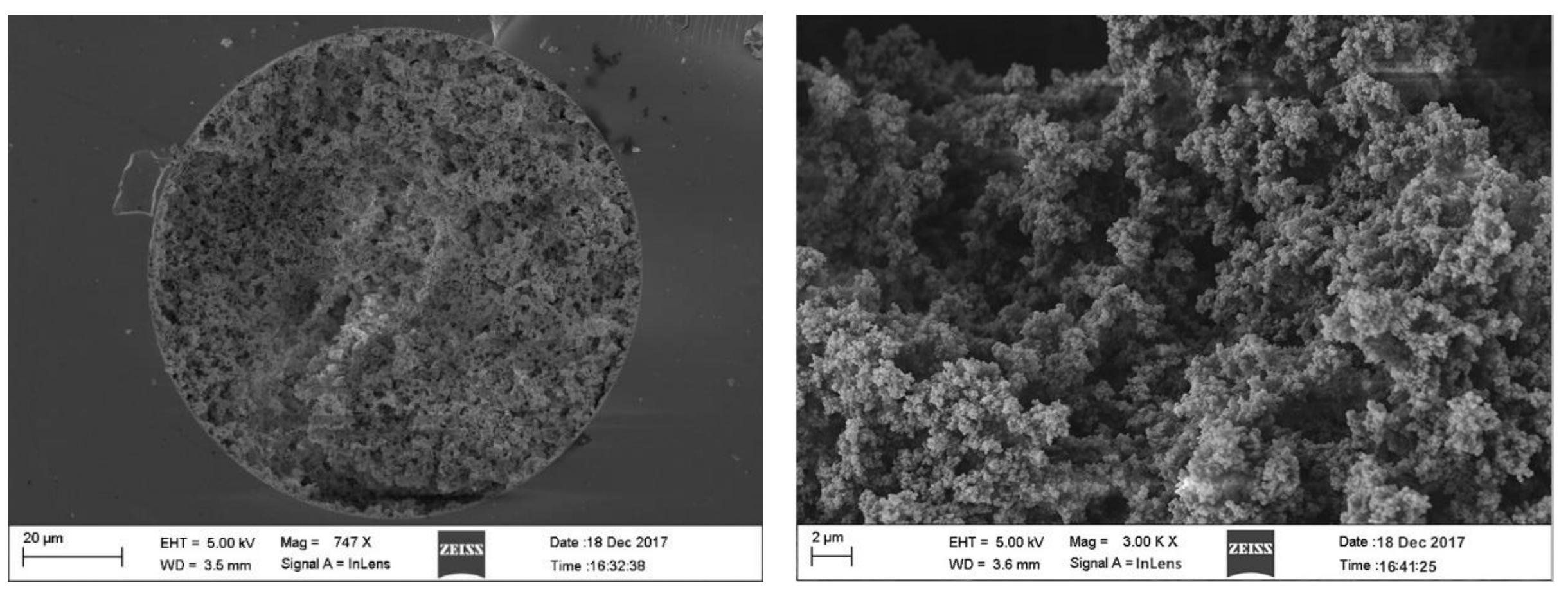
Figure 3
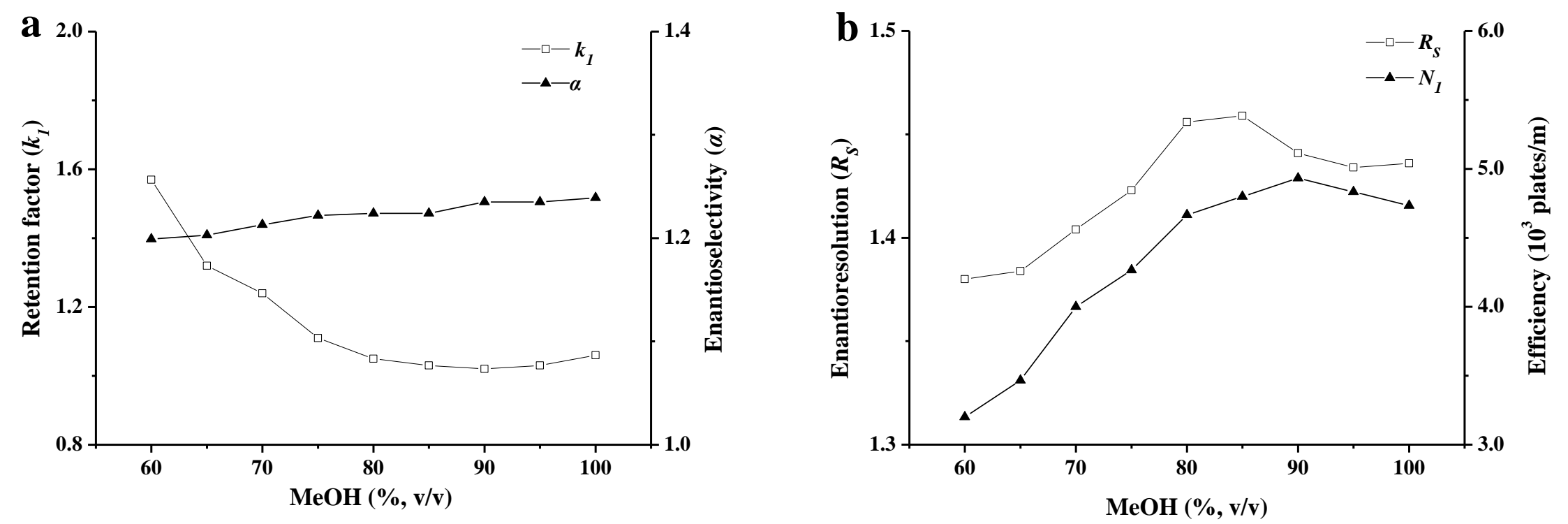
Figure 4
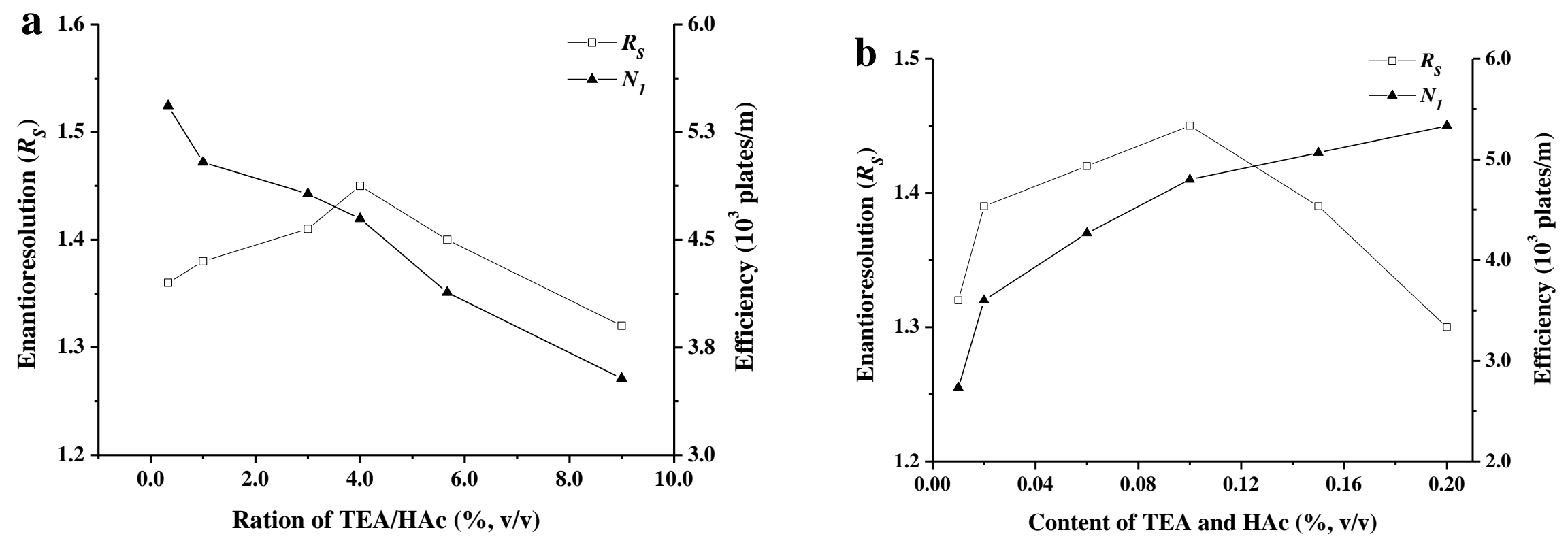
Figure 5
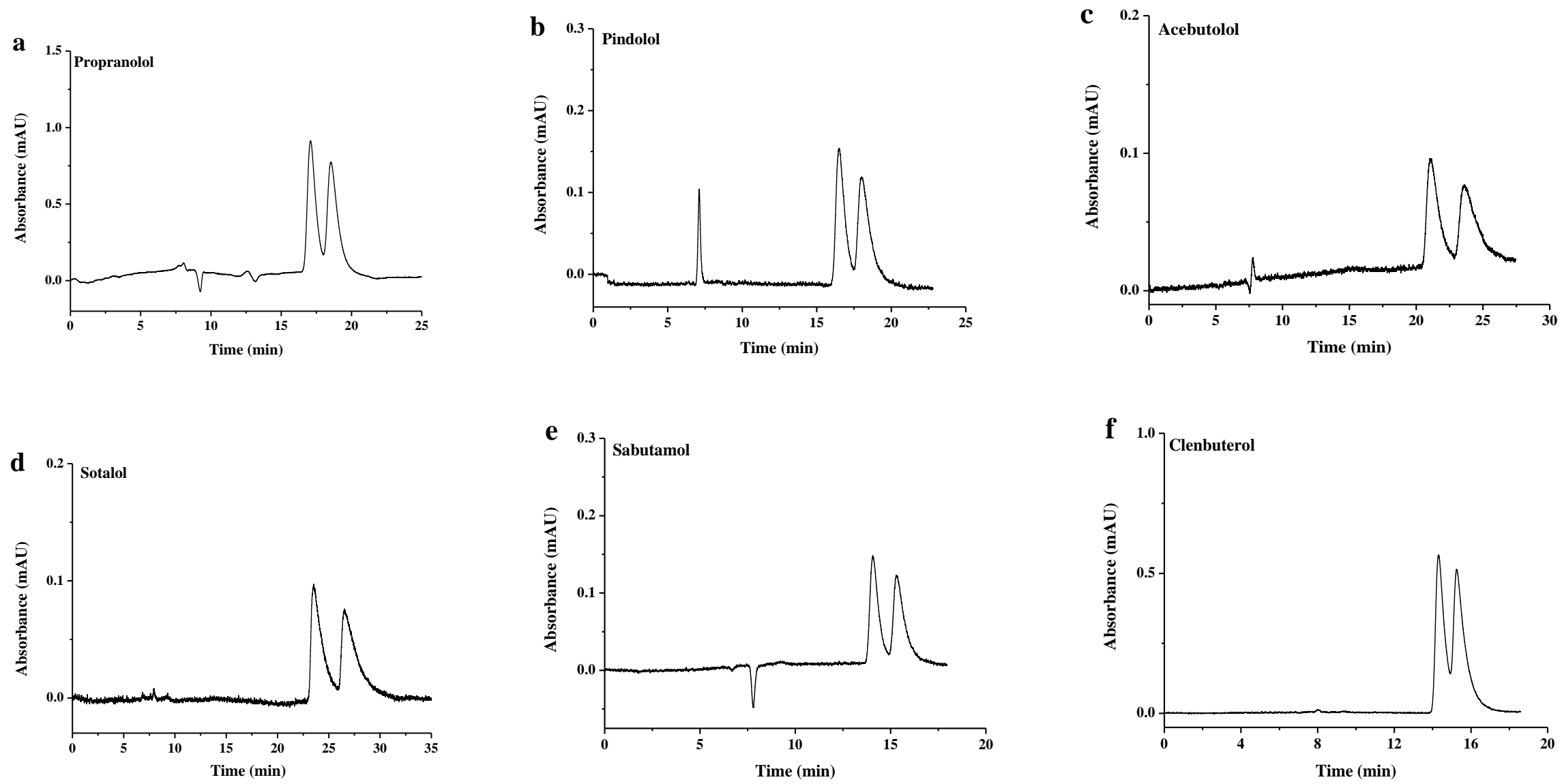
Figure 6
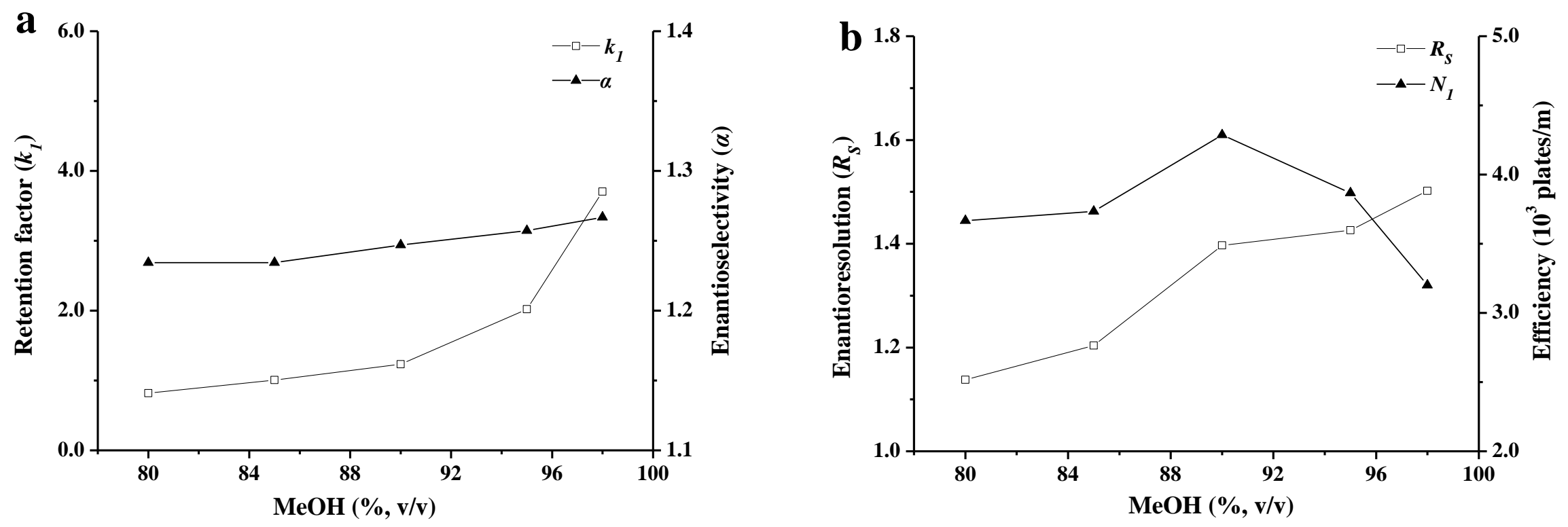
Figure 7
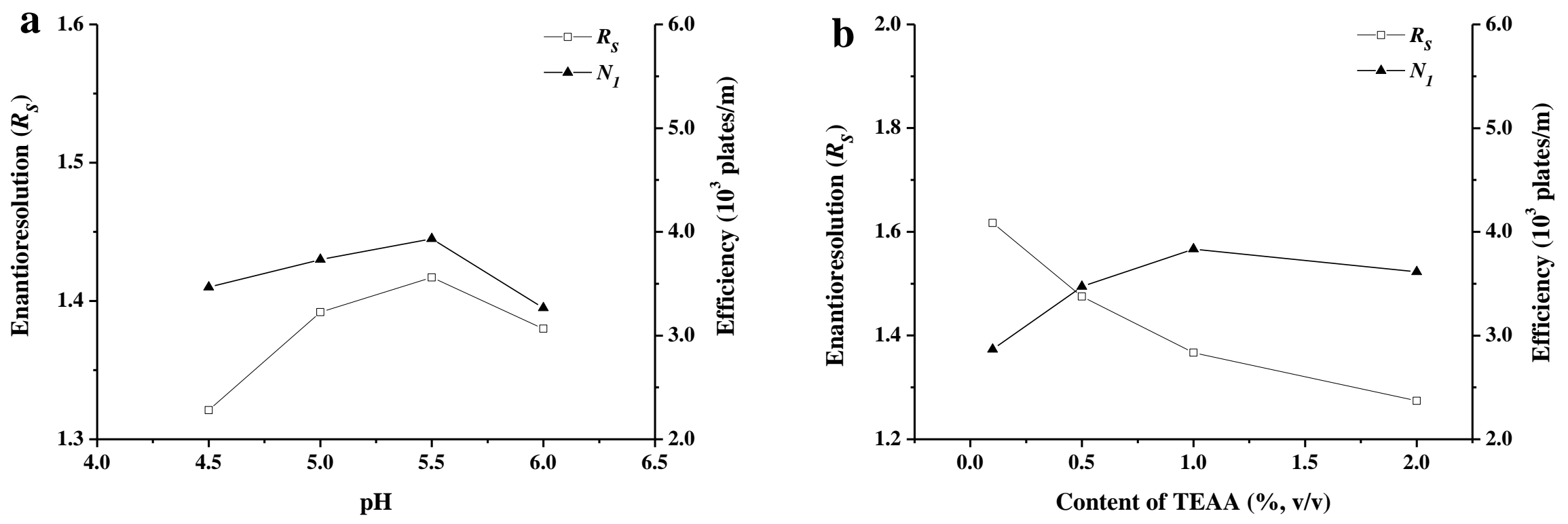
Figure 8
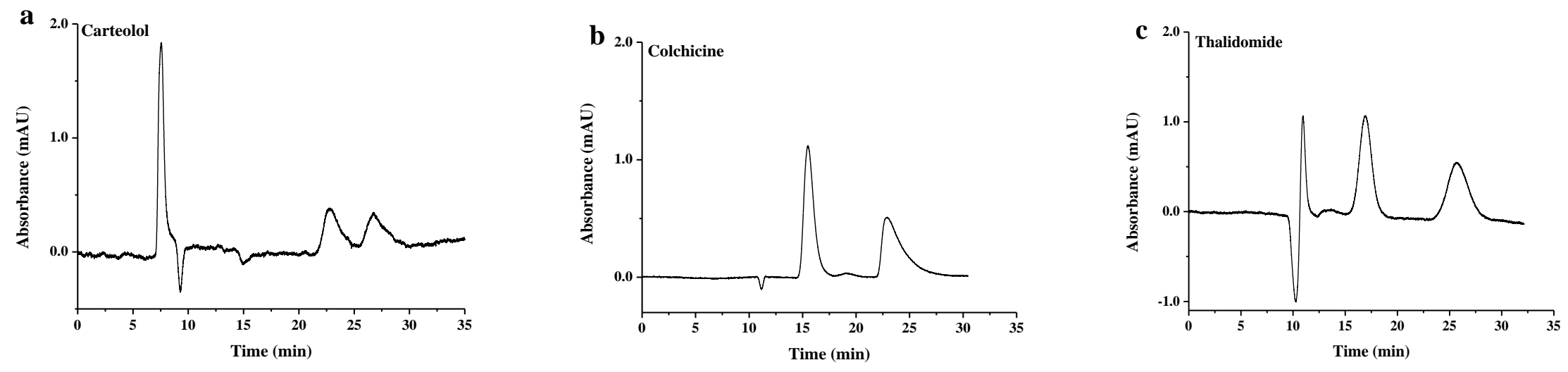
Table 1. Composition of the polymerization mixture used for the preparation of the poly (ICNEML-vancomycin-co-EDMA) monolith columns and their properties.

\begin{tabular}{|c|c|c|c|c|c|c|c|c|}
\hline \multirow{2}{*}{ Column } & \multicolumn{2}{|c|}{ Monomers $(\%, w / w)$} & \multicolumn{2}{|c|}{ Porogens $(\%, w / w)$} & \multicolumn{2}{|c|}{ Monomers: Porogens $(\%, w / w)$} & \multirow{2}{*}{$\begin{array}{c}\text { Backpressure } \\
\text { (MPa) }\end{array}$} & \multirow{2}{*}{$\begin{array}{c}\text { Enantioreso } \\
\text { lution }\end{array}$} \\
\hline & vancomycin & EDMA & $\mathrm{MeOH}$ & DMSO & Monomers & Porogens & & \\
\hline C1 & 75.0 & 25.0 & 75.0 & 25.0 & 29.0 & 71.0 & Too high & I \\
\hline $\mathrm{C2}$ & 75.0 & 25.0 & 75.0 & 25.0 & 25.0 & 75.0 & 7.5 & 1.45 \\
\hline $\mathrm{C3}$ & 75.0 & 25.0 & 75.0 & 25.0 & 21.0 & 79.0 & 3.4 & 0.37 \\
\hline C4 & 70.8 & 29.2 & 75.0 & 25.0 & 25.0 & 75.0 & 9.5 & 1.38 \\
\hline C5 & 79.2 & 20.8 & 75.0 & 25.0 & 25.0 & 75.0 & 3.6 & 0.51 \\
\hline C6 & 75.0 & 25.0 & 70.0 & 30.0 & 25.0 & 75.0 & 9.8 & 0.58 \\
\hline C7 & 75.0 & 25.0 & 80.0 & 20.0 & 25.0 & 75.0 & 4.7 & 0.94 \\
\hline
\end{tabular}

Conditions: column dimensions: $15 \mathrm{~cm} \times 100 \mu \mathrm{m}$ I.D.; mobile phase: MeOH/ACN/TEA/HAc (80/20/0.08/0.02, v/v/v/v); UV detection wavelength: 230 nm; total flow rate: $400 \mathrm{~nL} / \mathrm{min}$; injection volume: $20 \mathrm{~nL}$; sample: acebutolol. 
Table 2. Permeability of the poly (ICNEML-vancomycin-co-EDMA) monolith column

\begin{tabular}{|c|c|c|c|}
\hline Mobile phase & Relative polarity & Viscosity $\eta\left(\times 10^{-3} \mathrm{~Pa} \cdot \mathrm{s}\right)$ & Permeability $\mathrm{K}\left(\times 10^{-14} \mathrm{~m}^{2}\right)$ \\
\hline $\mathrm{ACN} / \mathrm{H}_{2} \mathrm{O}(50 / 50)$ & / & 0.820 & 1.97 \\
\hline $\mathrm{MeOH}$ & 0.762 & 0.544 & 2.78 \\
\hline $\mathrm{ACN}$ & 0.460 & 0.369 & 4.16 \\
\hline
\end{tabular}

Relative polarity and viscosity data of pure liquids were obtained from Ref. [26-27] 
Table 3. Reproducibility of the poly (ICNEML-vancomycin-co-EDMA) monolith columns

\begin{tabular}{ccccc}
\hline & \multicolumn{2}{c}{ Average retention factor (RSD) } & Average selectivity & Average resolution \\
& $k_{1}$ & $k_{2}$ & $\alpha(\mathrm{RSD})$ & $R_{s}$ (RSD) \\
\hline Column to column (n=6) & $1.31(2.36 \%)$ & $1.53(2.36 \%)$ & $1.17(2.02 \%)$ & $1.40(5.92 \%)$ \\
Run to run $(\mathrm{n}=6)$ & $1.27(1.98 \%)$ & $1.46(2.36 \%)$ & $1.15(1.57 \%)$ & $1.42(4.14 \%)$ \\
Day to day $(\mathrm{n}=6)$ & $1.25(3.03 \%)$ & $1.51(3.42 \%)$ & $1.21(1.13 \%)$ & $1.44(4.72 \%)$ \\
Batch to batch $(\mathrm{n}=6)$ & $1.29(2.72 \%)$ & $1.49(2.36 \%)$ & $1.16(1.79 \%)$ & $1.39(5.33 \%)$ \\
\hline
\end{tabular}

Conditions: column dimensions: $15 \mathrm{~cm} \times 100 \mu \mathrm{m}$ I.D.; mobile phase: $\mathrm{MeOH} / \mathrm{ACN} / \mathrm{TEA} / \mathrm{HAc}(85 / 15 / 0.08 / 0.02, \mathrm{v} / \mathrm{v} / \mathrm{v} / \mathrm{v})$; UV detection wavelength: $230 \mathrm{~nm}$; total flow rate: $400 \mathrm{~nL} / \mathrm{min}$; injection volume: $20 \mathrm{~nL}$; sample: acebutolol. 
Table 4. Enantioseparation of eight racemic compounds under the polar organic phase mode.

\begin{tabular}{|c|c|c|c|c|c|c|}
\hline Sample & $k_{1}$ & $k_{2}$ & $\alpha$ & $R_{S}$ & $N_{1}(\mathrm{~m})$ & $N_{2}(\mathrm{~m})$ \\
\hline Carteolol & 1.04 & 1.28 & 1.23 & 1.45 & 4500 & 4100 \\
\hline Propranolol & 1.04 & 1.21 & 1.17 & 1.38 & 5100 & 4300 \\
\hline Acebutolol & 1.26 & 1.48 & 1.17 & 1.43 & 4400 & 3900 \\
\hline Pindolol & 1.07 & 1.23 & 1.15 & 1.32 & 3900 & 3200 \\
\hline Tertaolol & 0.66 & 0.81 & 1.22 & 1.39 & 5500 & 4600 \\
\hline Sotalol & 1.65 & 2.01 & 1.22 & 1.42 & 4100 & 3300 \\
\hline Clenbuterol & 0.67 & 0.78 & 1.16 & 1.26 & 4600 & 4100 \\
\hline Salbutamol & 0.74 & 0.88 & 1.18 & 1.47 & 4900 & 4100 \\
\hline
\end{tabular}

Experimental conditions are the same as in Fig. 4. 
Table 5. Enantioseparation of three racemic compounds under the reversed phase mode.

\begin{tabular}{|c|c|c|c|c|c|c|}
\hline Sample & $k_{1}$ & $k_{2}$ & $\alpha$ & $R_{S}$ & $N_{1}(\mathrm{~m})$ & $N_{2}(\mathrm{~m})$ \\
\hline Carteolol & 2.18 & 2.72 & 1.24 & 1.59 & 3800 & 2500 \\
\hline Colchicine & 0.41 & 1.08 & 2.62 & 2.92 & 6200 & 3300 \\
\hline Thalidomide & 0.52 & 1.33 & 2.55 & 2.85 & 5100 & 4200 \\
\hline
\end{tabular}

Experimental conditions are the same as in Fig. 7. 


\section{SUPPORTING INFORMATION}

\section{A facile and efficient single-step approach for the fabrication of vancomycin functionalized polymer-based monolith as chiral stationary phase for nano-liquid chromatography}

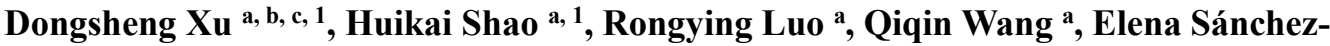 López $^{\mathrm{c}}$, Salvatore Fanali d, Maria Luisa Marina ${ }^{\mathrm{c}, \mathrm{e}}$, Zhengjin Jiang, b, *}

${ }^{a}$ Institute of Pharmaceutical Analysis, College of Pharmacy, Jinan University, Guangzhou 510632, China.

${ }^{b}$ Department of Pharmacy and Guangdong Province Key Laboratory of Pharmacodynamic Constituents of Traditional Chinese Medicine \& New Drug Research, Jinan University, Guangzhou 510632, China.

${ }^{c}$ Departamento de Química Analítica, Química Física e Ingeniería Química, Universidad de Alcalá, Ctra. Madrid-Barcelona Km. 33.600, 28871 Alcalá de Henares (Madrid), Spain.

${ }^{d}$ PhD School in Natural Science and Engineering, University of Verona, Strada Le Grazie, 15 37129 Verona, Italy.

e Instituto de Investigación Química "Andrés M. del Río" (IQAR), Universidad de Alcalá, Ctra. Madrid-Barcelona Km. 33.600, 28871 Alcalá de Henares (Madrid), Spain.

${ }^{1}$ These authors contributed equally to this work.

\footnotetext{
* Corresponding authors. Tel: +34 918854935

${ }^{*}$ Corresponding authors. Tel: +86 2085223604

E-mail: mluisa.marina@uah.es (M. L. Marina),jzjjackson@hotmail.com (Z. J. Jiang)
} 
Figure S1. HR-ESI-MS of ICNEML-vancomycin.

\section{Elemental Composition Report}

Page 1

\section{Single Mass Analysis}

Tolerance $=5.0 \mathrm{mDa} /$ DBE: $\min =-1.5, \max =50.0$

Element prediction: Off

Number of isotope peaks used for i-FIT $=3$

Monoisotopic Mass, Even Electron lons

349 formula(e) evaluated with 3 results within limits (up to 50 closest results for each mass)

Elements Used:
C: $0-100$
$\mathrm{N}: 10-10$
O: $0-50$
Cl: 2-2

$2016082971175(1.421)$

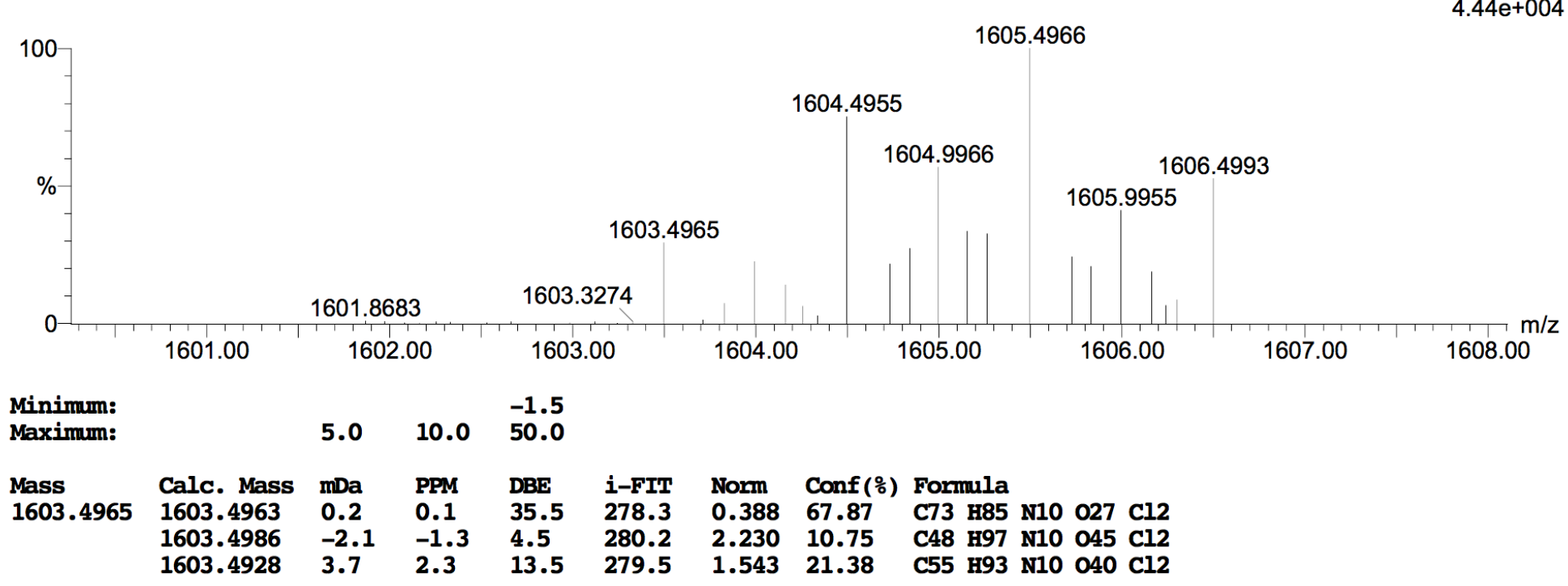

